Techniques \& Culture

Revue semestrielle d'anthropologie des techniques

$51 \mid 2009$

Des Choses, des gestes, des mots

\title{
Dynamiques, Structures et science en fabrique
}

Editorial

Frédéric Joulian

\section{(2) OpenEdition}

Journals

Édition électronique

URL : https://journals.openedition.org/tc/4515

DOI : $10.4000 /$ tc. 4515

ISSN : 1952-420X

Éditeur

Éditions de l'EHESS

Édition imprimée

Date de publication : 15 août 2009

Pagination : 4-7

ISBN : 978-2-7351-1235-7

ISSN : 0248-6016

Référence électronique

Frédéric Joulian, «Dynamiques, Structures et science en fabrique », Techniques \& Culture [En ligne], 51 | 2009, mis en ligne le 12 novembre 2009, consulté le 29 septembre 2022. URL : http:// journals.openedition.org/tc/4515; DOI : https://doi.org/10.4000/tc.4515 


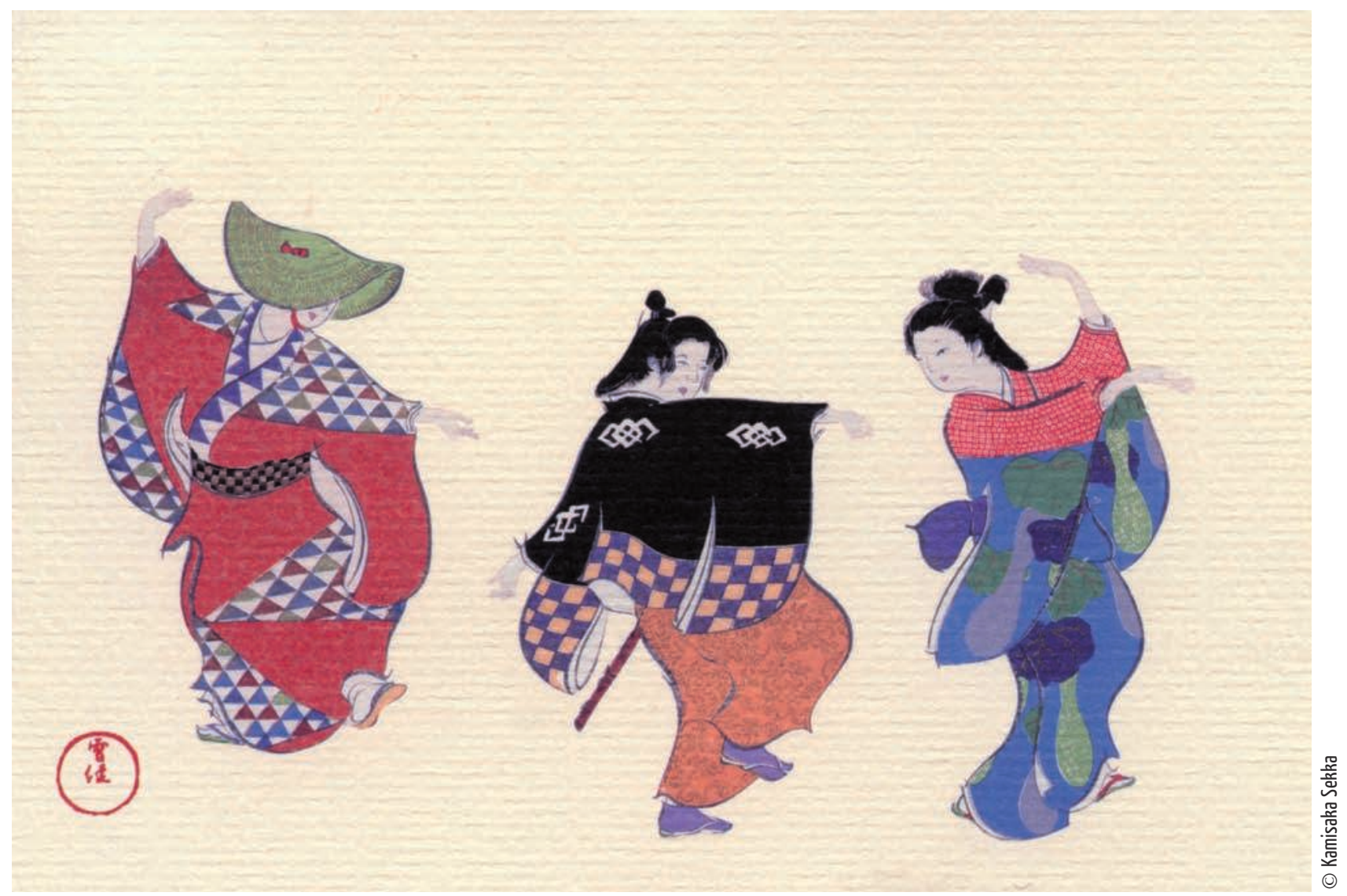




\section{DYNAMIQUES, STRUCTURES}

\section{et science en fabrique}

\section{Dynamiques}

Le Thema d'aujourd'hui, « Repenser les dynamiques culturelles » s'inscrit clairement dans la ligne théorique et empirique que la revue dessine depuis sa fondation en 1983 et sa relance en 2008. Le dossier piloté par Olivier Gosselain, Renaud Zeebroek et Jean-Michel Decroly de l'Université libre de Bruxelles est le fruit d'un travail interdisciplinaire important sur les modes de transmission des objets et des pratiques en Afrique de l'Ouest. Ce projet d'analyse multi-échelle intègre archéologues, ethnologues, géographes et linguistes et livre aujourd'hui un Thema de très haut niveau d'intégration. Il renvoie à un travail au long cours d'un groupe de chercheurs qui ont appris la langue du collègue avant même de démonter et remonter leurs instruments d'analyse, de circonscrire ensemble des terrains d'enquête et de suivre des objets (potirons, salades casseroles...), fils rouges matérialisant des parcours de vie, dans l'espace et le temps. En même temps que les théories, les objets ou les terrains étaient décortiqués, surgissait également une position empirique et critique de plus en plus forte. Et si la mode 2009 est aux « patrimoines immatériels », l'analyse présentée ici du phénomène d'halloween est délibérément pragmatique. Les représentations sont analysées dans leurs mises en pratiques et sont objectivées et travaillées comme des objets. Avec ce Thema, on est à mille lieux d'une approche normative. Par l'étude de cas, les auteurs s'attaquent aux « dessous » de l'expression, il faut l'avouer un peu vague, de « dynamiques culturelles » et cela, en en cherchant 
des configurations stabilisées, des évolutions dans le temps, des déplacements dans l'espace, des changements de formes et fonctions, en fait, toutes sortes de configurations qu'analysaient autrefois, de façon séparée, anthropologues et historiens. Ces conduites des hommes en société sont « dynamiques » et c'est en tant que telles qu'elles sont étudiées, ici via l'étude de la culture matérielle, qui permet tout à la fois de les suivre et de les objectiver. En ce sens, ce numéro peut être lu comme une sorte de manifeste invitant les chercheurs à reposer les pieds sur terre, à réagir tout à la fois à la surthéorisation mais aussi à une certaine démission empirique (et méthodique) des sciences de l'homme qui abandonnent la partie au positivisme caricatural des sciences cognitives ou des sciences biologiques (Messoudi et al. 2006). En conclusion du Thema et à l'inverse de ce réductionnisme donneur de leçons, l'article de Jean Lave sur les opérations cognitives des tailleurs libériens est une des plus belles leçons d'intelligence et de modestie scientifique que l'on puisse lire en anthropologie. Revenant sur son parcours d'ethnologue en Afrique dans les années 1970, elle montre comment les cadres analytiques de la psychologie cognitive et de la pédagogie formelle ont été mis à l'épreuve du terrain puis progressivement redéfinis afin de rendre au mieux les opérations mentales d'apprentissage en jeu dans la vie quotidienne des apprentis et de leurs patrons. Par les dialogues, par l'évocation de vies partagées à Monrovia, elle renvoie les modélisateurs à leurs gadgets, les scientistes à leurs règles et rend enfin justice à une véritable anthropologie cognitive, il va sans dire, pratiquement et socialement située.

\section{Structures}

J'aimerais aussi, en cette année 2009, centenaire de la naissance de Claude LéviStrauss, retisser un lien - que nous développerons dans un prochain numéro entre deux traditions anthropologiques françaises, celle de Lévi-Strauss et celle de Leroi-Gourhan, traditions qui ont évolué indépendamment durant la seconde moitié du XX $X^{e}$ siècle et dont il convient à présent d'assumer pleinement le double héritage intellectuel et politique.

Je laisse donc la parole à Claude Lévi-Strauss évoquant l'œuvre d'André Leroi-Gourhan (conférence de 1987):

Il me semble que, parlant de choses très différentes, nous les abordions et les traitions dans le même esprit. De sorte que, si Leroi-Gourhan est allé de l'étude des techniques, comme poussé par une nécessité invincible, jusqu'à élaborer toute une mythologie (puisque, au fond, son apport essentiel à la préhistoire de l'art occidental, c'est d'avoir restitué des linéaments de ce qu'a pu être la pensée mythique, il avait soin de ne pas dire religieuse, mais la pensée mythique de nos lointains ancêtres préhistoriques), je faisais de mon côté la démarche inverse: partant de la mythologie, j'étais obligé de m'improviser apprenti botaniste, apprenti zoologiste et aller vers ces faits-objets (c'est une expression de Leroi-Gourhan) qui sont unis aux faits-idées - ce sont là toujours ses mots que je cite - par toute une série continue d'intermédiaires. Et ce qui rend, entre autres, son apport irremplaçable, c'est d'avoir enseigné à ses étudiants, c'est de nous avoir enseigné à tous, qu'il est impossible de parler de quoi que ce soit sans savoir d'abord de quoi on parle. « Pénétrer dans le domaine technologique, disait-il, suppose une formation de technicien au sens étroit. » Rien mieux qu'un tel précepte ne peut nous mettre à l'abri de ces tentations dont nous sentons aujourd'hui le danger: 
d'une sorte de verbiage sociologique ou sémiotique qui croit possible de parler de la symbolique ou de la fonction significative de tels ou tels objets matériels sans s'être d'abord assuré de ce qu'ils sont en eux-mêmes et comment ils ont été fabriqués; un peu comme si on prétendait parler des mours de telle ou telle famille animale sans rien savoir de son anatomie ou de sa physiologie.

\section{Et science en fabrique}

Avec le numéro 51 de Techniques \& culture, nous poursuivons la mise en place de la nouvelle formule « texte et image ». Elle ne surgit bien évidemment pas définitive aux premières livraisons, mais progresse, par adaptations successives, du fond et de la forme à la ligne éditoriale présentée dans les deux précédents éditoriaux. Nous ne sommes pas et ne serons jamais à l'heure du « préfabriqué », du « ready-made » mais bien à celle de l'artisanat scientifique et éditorial. Il ne peut en être autrement: la science bricole, forge ses instruments, les adapte; l'éditeur scientifique procède de même, visant un lectorat plus large. Le numéro inaugural de la nouvelle série, sur papier couché, permettait la quadrichromie et la rupture graphique, mais trop épais, donnait aussi un aspect contraire à la philosophie généraliste et ouverte de la revue. Son poids important contrevenait à l'option « lecture pour tous et n'importe où ». Ce numéro 51 s'allège donc en poids et nous espérons trouver une qualité de papier permettant de restituer, en plus des textes scientifiques, des œuvres de photographes exigeants, le tout dans une formule économiquement plus viable.

Rappelons également que le travail éditorial s'appuie sur un fonctionnement collectif, en deux ou trois temps, qui réunit des chercheurs de différentes disciplines autour d'un thème commun et organise - sur la base d'exposés et de débats contradictoires - à chaque parution, un numéro inédit. La préparation du prochain numéro a fait l'objet de trois rencontres scientifiques (en France et en Angleterre) mené en collaboration avec le Journal of Material Culture. D'autres sont déjà lancés: sur l'habitat précaire, sur les modes de description des activités, sur les traditions japonaises et françaises d'observation de la nature, des techniques et des hommes.

La partie Varia se nourrit d'articles reçus ou invités que nous acceptons, refusons ou retravaillons parfois en profondeur avec les auteurs. Dans ce numéro, nous proposons deux enquêtes ethnographiques, l'une sur les dimensions technique et sémiotique et l'esthétique fonctionnelle des vanneries sahariennes, l'autre sur une soupe funéraire chez les Mongols, recherche qui illustre parfaitement les inversions techniques et symboliques, reflets de croyances distinctes et simultanément à l'œuvre. Ces deux exemples nous rappellent, s'il le fallait encore, tout l'intérêt d'une ethnographie détaillée et les vertus heuristiques d'approches fondées sur les analyses savantes de la culture matérielle. La troisième rubrique prévue, Curiosa, fondée sur les parutions, expositions, objets et musées sera développée dans le numéro suivant qui portera sur un renouvellement du dialogue franco-anglais en matière d'analyse de la culture matérielle, qu'elle soit prise sous l'angle de sa production comme celui de la consommation et des usages.

Frédéric Joulian
Lévi-Strauss, C.: « Nous avons lui et moi essayé de faire à peu près la même chose », in André Leroi-Gourhan ou les voies de l'homme, collectif, 1988, Paris, Albin Michel: 201-206.

Mesoudi, A., Whiten, A. \& Laland, K.N., 2006, " Towards a unified science of cultural evolution », Behavioral and Brain Sciences $29(4): 329-347$ 